\title{
The acoustic repertoire of wild common bottlenose dolphins (Tursiops truncatus) in Walvis Bay, Namibia
}

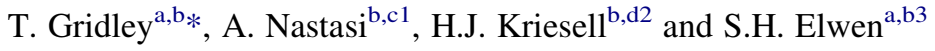 \\ ${ }^{a}$ Mammal Research Institute, Department of Zoology and Entomology, University of Pretoria, \\ Private Bag X20, Hatfield 0028, Gauteng, South Africa; \\ ${ }^{b}$ Namibian Dolphin Project, PO Box 5209, Walvis Bay, Erongo, Namibia; \\ ${ }^{c}$ Sapienza Universita`di Roma, Dipartimento di Scienze della Terra, Piazzale Aldo Moro 5, 00185 \\ Rome, Italy; \\ ${ }^{d}$ Centre Scientifique de Monaco (CSM), Départment de Biologie Polaire, LIA-647 BioSensib (CSM- \\ CNRS-UdS), 8 Quai Antione Ier, 98000 Monaco
}

\begin{abstract}
Describing the repertoire of sounds produced by wild cetaceans is necessary for understanding their function, for acoustic population monitoring and for measuring the potential influence of anthropogenic impact. Geographic variation in the types and parameters of sounds makes regional assessment of vocal behaviour necessary. We describe the acoustic repertoire of a small population of common bottlenose dolphins (Tursiops truncatus) inhabiting Walvis Bay, Namibia from recordings made over 59 encounters (72 h) between 2009 and 2012. The characteristics of burst pulse (BP) sounds, low-frequency narrow-band (LFN) sounds, brays, whistles and chirps are described. The BP sounds identified were generated at 150-1050 pulses per second, and most were short, lasting less than $1 \mathrm{~s}$ in duration. Bottlenose dolphins from Walvis Bay produce the lowest frequency LFN sounds described for the species. Whistles ranged in frequency from 1.58 to 23.24 $\mathrm{kHz}$, and the mean acoustic parameters were within the range of those described from other geographic regions. Chirps were identified infrequently and usually as single occurrences. Although several sound types were often produced in close temporal succession, we found little evidence of stereotyped bray production, even during recordings of animals feeding. Our results demonstrate geographic variation in both the characteristics and sound types used by bottlenose dolphins and highlight the importance of regional data collection as a pre-curser to passive acoustic monitoring programmes.
\end{abstract}

Keywords: bottlenose dolphin; Tursiops truncatus; low-frequency narrow-band; burst pulse; whistle; Namibia

\section{Introduction}

Characterizing the repertoire of sounds produced by wild cetaceans is necessary for understanding the function of these sounds, for monitoring populations using passive acoustic monitoring (PAM) and for determining the potential influence of man-made acoustic pollution on vocal communication systems. Regional assessments of vocal behaviour are necessary as geographic variation between populations is common in the sound types (Boisseau 2005; Simon et al. 2006; van der Woude 2009), acoustic parameters (Morisaka et al. 2005; Rossi-Santos and Podos 2006; Samarra et al. 2010) and temporal production (Jones and Sayigh 2002) of vocalizations. Variation in the repertoire and acoustic characteristics of sounds produced by a population may result from ecological specialization (Barrett-Lennard et al. 1996; Janik 2000a; Nowacek 2005; Simon et al.

*Corresponding author. Email: tessgridley@yahoo.co.uk 
2007) or cultural processes (Noad et al. 2000; Rendell and Whitehead 2003) and may reflect differing genetic, morphological or social characteristics (Long et al. 1998; Mitani et al. 1999; May-Collado et al. 2007; Kikusui et al. 2011) of species or populations. As very few studies of cetacean acoustic behaviour have ever taken place in Africa (Elwen et al. 2011), regional assessments of vocalization characteristics provide a necessary baseline before more complex behavioural questions can be addressed or automated PAM programmes can be implemented (Gillespie et al. 2013).

Several studies have investigated the acoustic behaviour of common bottlenose dolphins (Tursiops truncatus) in the wild (e.g. dos Santos et al. 1995; Janik 2000a, 2000b; Cook et al. 2004; Boisseau 2005; dos Santos et al. 2005; Frankel et al. 2014). However, the majority of research has focused on echolocation clicks and whistles (e.g. Au et al. 1982; Jones and Sayigh 2002; Quick and Janik 2008; Díaz López 2011) without looking at the whole repertoire of vocal production. Bottlenose dolphin echolocation clicks are high intensity, short duration, broadband sounds with ultrasonic peak frequencies, usually produced in rapid succession (click trains) for the detection and discrimination of targets (Au 1993). During echolocation, the dolphin listens to echoes returning from targets present over a short range. This use of sound during echolocation differs fundamentally from that in communication, whereby animals encode information in their signals that can be decoded by a receiver (Janik 2009). The most commonly studied communication signal in dolphin repertoires are whistles; frequency-modulated, narrowband sounds, which in Tursiops spp. range between 0.8 and $28.5 \mathrm{kHz}$ in frequency (Schultz and Corkeron 1994; May-Collado and Wartzok 2008). Whistles are principally used in social contexts (Jones and Sayigh 2002; Quick and Janik 2008). Approximately, $52 \%$ of those produced by freely interacting animals are signature whistles (Cook et al. 2004), which are used to convey identity information (Janik et al. 2006), facilitate group contact (Janik and Slater 1998; Quick and Janik 2012) and address conspecifics (King and Janik 2013).

The presence of various other sounds within the bottlenose dolphins' repertoire has long been acknowledged, even though these sounds have received much less attention. Many of these vocalizations appear to be universal (Boisseau 2005). For example, burst pulse (BP) sounds are broadband discrete aural packets of pulses that due to their high repetition rate appear in spectrograms as harmonic bands that are perceived as a continuous sound by the human ear (Watkins 1967; Herzing 2000). Although BP sound comprise a large proportion of the vocal repertoire (Herzing 2000), sound classification based on human-perceived aural qualities and non-standardized analysis techniques has made cross population comparisons difficult (Herzing 2000; Boisseau 2005). The exact function of BP sounds remains unclear (Janik 2009) and may vary with species and context. There is growing evidence to support a principal role in communication (Lammers et al. 2003b; Rankin et al. 2007; Vaughn-Hirshorn et al. 2012) rather than echolocation, as the inter-click interval (ICI, also referred to as the inter-pulse interval, IPI), which may be $10 \mathrm{~ms}$ or less (Lammers et al. 2003a), exceeds the two-way propagation time thought necessary for receiving the echoes of individual clicks (Ivanov 2004). However, for long-range target discrimination, BP sounds may be used in an echolocation capacity (Ivanov 2004; Finneran 2013).

Other bottlenose dolphin vocalizations, poorly described from an acoustic and behavioural perspective, include low-frequency moans (van der Woude 2009) and lowfrequency narrow-band (LFN) sounds (Schultz et al. 1995; Simard et al. 2011). Like BP sounds, their function in the dolphin acoustic repertoire has yet to be resolved. LFN sounds are short-duration $(<1 \mathrm{~s})$ tonal sounds, usually under $1 \mathrm{kHz}$ in frequency 
(Schultz et al. 1995; Simard et al. 2011). Although only recently described in detail (Simard et al. 2011), they have likely always existed in the repertoire of bottlenose dolphins, perhaps classified under a different name. For example, dos Santos et al. (1995) refer to low-frequency transient sounds as 'gulps'. Lasting 100-180 ms in duration and with energy concentrated at $300 \mathrm{~Hz}$, these are likely to be synonymous with LFN sounds. Similar sounds have been described in other delphinid species, for example the 'grunts' of Indo-Pacific humpback dolphins Sousa chinensis (Van Parijs and Corkeron 2001) and Risso's dolphins (Grampus griseus) (Corkeron and Van Parijs 2001) resemble the LFN sounds of bottlenose dolphins. Being low frequency, these sounds are difficult to detect as they may be masked by concurrent low-frequency noise sources. Consequently, they may have been under-reported in studies that focused on other, more obvious vocalizations.

Dolphins can combine sound types to produce distinct vocal units (dos Santos et al. 1995; Herzing 2000; Janik 2000a; Blomqvist et al. 2005). These units may play a functional role within the vocal repertoire, which differs to that of the individual components. For example, dos Santos et al. (1995) describe bray vocalizations, which are generated when low-frequency un-pulsed transient sounds (i.e. probable LFN sounds) are alternated in a rhythmic fashion with other types of signals. In Scotland, the alternate signal in bray vocalizations are BP sounds and bray production is correlated with feeding on salmonids (Janik 2000a). Being low frequency in nature, Janik (2000a) proposes that bray vocalizations act to manipulate prey behaviour and therefore may have developed in dolphins to exploit the perceptual systems of their salmonid prey.

This study focuses on the acoustic repertoire of the only inshore population of common bottlenose dolphins (T. truncatus) inhabiting the southern African coastline. We provide the first description of the prominent sound types used across a range of behavioural states and compare their characteristics to those of other populations.

\section{Methods}

Data were collected in three different field seasons between 2009 and 2012 in Walvis Bay $\left(22^{\circ} 57^{\prime} \mathrm{S} ; 14^{\circ} 30^{\prime} \mathrm{E}\right)$ a $10 \times 10 \mathrm{~km}$ north-facing bay located along the central coast of Namibia (see Figure 1, Table 1). The Walvis Bay bottlenose dolphin population is small (approximately 100 individuals, author's unpublished data), and apparently isolated from other bottlenose dolphins populations along the west coast of Africa (Findlay et al. 1992; Best 2007). As the only embayment of significant size along the Namibian coastline, Walvis Bay represents the core habitat for this population, providing shelter from strong south westerly swells and good resting and foraging opportunities.

Local weather conditions create calm and flat seas in the bay during the morning with stronger winds in the afternoons (usually Beaufort 4 or higher). Therefore, boat surveys to conduct focal follows (Altmann 1974) of groups were mostly carried out in the mornings when the probability of finding dolphins was the highest. When dolphins were sighted, an encounter was begun and acoustic data as well as standard information on the estimated group size, dispersion and number of calves were documented. A concentrated period of photo-identification was also undertaken at the start of each encounter to determine the individuals present. In order to minimize disturbance, no focal follow lasted more than $4 \mathrm{~h}$ and most lasted between 1 and $2 \mathrm{~h}$. Dolphin groups were approached from the back or the side, carefully adjusting the vessel speed to match that of the dolphin group or turning the engines off to reduce the disturbance of the engine noise on the dolphins' surface and acoustic behaviour. An established dolphin watching industry operates in Walvis Bay 


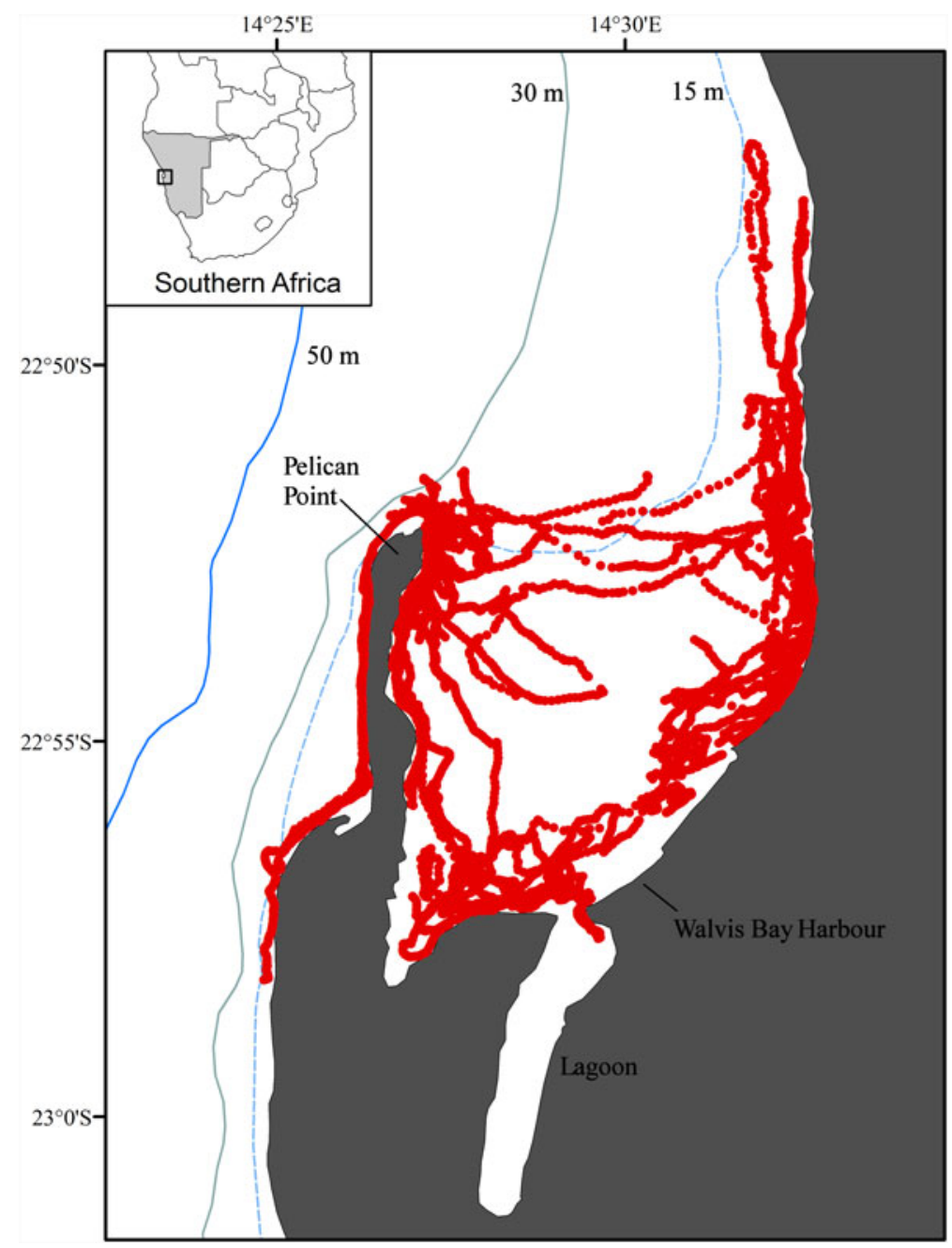

Figure 1. Map of the study area, Walvis Bay, Namibia showing the GPS tracks collected of focal follows during which acoustic data were collected.

(Leeney 2014) and recordings were often made in the presence of one or more tour boats operating with 4-stroke outboard or inboard diesel motors, which were mostly idling or travelling slowly.

Table 1. Vessels and equipment used over 3 years of research between 2009 and 2012.

\begin{tabular}{|c|c|c|}
\hline Data collection & Research vessel & Recording device \\
\hline February-March 2009 & $\begin{array}{l}8 \mathrm{~m} \text { ski boat fitted with twin } 80 \mathrm{hp} 4 \text {-stroke } \\
\text { Honda engines }\end{array}$ & $\begin{array}{l}\text { Edirol UA-25 sound card } \\
\text { to PC }\end{array}$ \\
\hline June-August 2011 & $\begin{array}{l}5.7 \mathrm{~m} \text { rigid hulled inflatable boat (RHIB) } \\
\text { fitted with twin } 50 \mathrm{hp} 2 \text {-stroke Mercury } \\
\text { engines }\end{array}$ & Zoom $\mathrm{H} 4 \mathrm{n}$ digital recorder \\
\hline July-August 2012 & $\begin{array}{l}5.7 \mathrm{~m} \text { RHIB fitted with twin } 60 \mathrm{hp} 4 \text {-stroke } \\
\text { Yamaha engines }\end{array}$ & Zoom H4n digital recorder \\
\hline
\end{tabular}


Underwater acoustic recordings of dolphin vocalizations were made using the equipment reported in Table 1. Throughout the study, we used a single-element High-Tec HTI-96-MIN hydrophone, frequency response of $2 \mathrm{~Hz}-30 \mathrm{kHz}( \pm 1 \mathrm{~dB})$, sensitivity of $-170 \mathrm{~dB}$ re $1 \mathrm{~V} / \mu \mathrm{Pa}$. The recorders used (Table 1) sampled the data at $96 \mathrm{kHz}$. The hydrophone was weighted with a 1-cm-diameter steel chain and lowered 2-3 $\mathrm{m}$ below the water surface. When dolphins were found in waters $<3.5 \mathrm{~m}$ deep, the hydrophone depth was reduced accordingly. Acoustic recordings were made whenever possible when the research vessel was stationary, idling or travelling slowly (less than $8 \mathrm{~km}$ ). However, in certain encounters recordings could not be made, were interrupted or terminated, for instance when dolphins were positioned in the surf zone, in shallow waters or when groups were engaged in fast travel.

Auxiliary data on group behaviour was point sampled every 3 min during encounters. Bottlenose dolphin behaviour was assessed using a focal group sampling method whereby we assigned the predominant group behaviour for the majority $(>50 \%)$ of the group to a predetermined set of behavioural states (Mann 1999). If appropriate, we assigned the behaviour of the remaining group to a secondary behavioural category. Behavioural states were classified as: milling, surface feeding, socializing, travelling and resting based on Lusseau (2003) and were designed to be mutually exclusive but together describe the entire observable behavioural budget of the population.

\section{Acoustic analysis}

Our analysis focuses on the identification and description of sounds produced by bottlenose dolphins during encounters in Walvis Bay (Figure 2). Sound types were identified in the spectrogram display of Adobe Audition (Ver. 4.0), and Raven Pro 1.4 (Cornell Bioacoustic Research Program 2011) software by visually and aurally scanning the recordings. The spectrogram display was created using a Hanning window with an FFT of 512 for tonal sounds and an FFT of 1024 for the identification of BPs. We noted the occurrence of all sounds thought to be generated by dolphins and focused our analysis on four sound types, namely (a) BP sounds, (b) LFN sounds, (c) whistles and (d) chirps, and one combination sound - the 'bray', which have been previously described in other regions (see below for further definitions). Echolocation clicks (Au 1993) and 'pops'

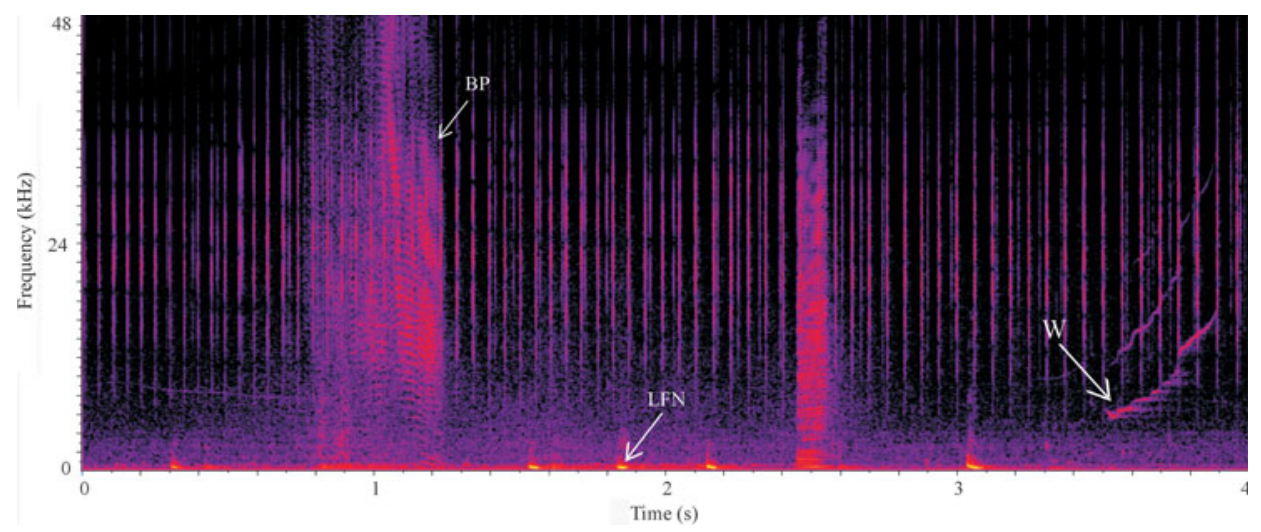

Figure 2. A sample spectrogram that includes three types of sound recorded from common bottlenose dolphins in Namibia and described in this study: BP sounds, whistles (W) and LFN sounds; note echolocation clicks in the background (FFT: 1024, Hanning Window, 50\% overlap). 
(Nowacek 2005) were more broadband than our equipment could record and not further analysed as echolocation clicks are already well described in the literature (Au 1993) and pops were hard to consistently distinguish from ambient noise.

BP sounds are generated when broadband pulses cf. clicks (few $\mathrm{Hz}$ to $>48 \mathrm{kHz}$ ) are emitted at high repetition rates (pulses/s) with intervals of only a few $(0.5-10) \mathrm{ms}$ (Lammers et al. 2003a). As BP sounds and click trains lie on a continuum relative to pulse repetition rate (Murray et al. 1998; Herzing 2000), we defined BP sounds as those calls that in the spectrogram display (FFT 1024 at a sampling rate of $96 \mathrm{kHz}$ ) appear as horizontal harmonic banded sounds in which clicks were visually and aurally indiscernible (Watkins 1967). The FFT size we used to identify BP sounds is consistent with other studies (Nemiroff and Whitehead 2009; Frankel and Yin 2010; Henderson et al. 2011) and differs from the spectrogram display used for the analysis of tonal calls. As the sampling rate of $96 \mathrm{kHz}$ was not adequate to capture the high frequency component of BP sounds, there was no attempt to analyse the frequency composition of these sounds. Rather, the temporal and pulse rate characteristics of BP sounds were determined where possible. To calculate pulse repetition rate, the number of pulses in each BP was counted manually through visual inspection of the waveform display in Raven and expressed as pulses per second (p/s). If the number of pulses was not entirely quantifiable using this method, the frequency spacing between the harmonics was measured in the spectrogram display close to the beginning, middle and end of each signal to determine the average repetition rate for that signal (Watkins 1967), which was again converted to p/s.

LFN sounds are tonal signals with a short duration $(<1 \mathrm{~s})$ and confined to low frequencies $(<5 \mathrm{kHz}$, Simard et al. 2011, Figure 2). To increase the probability of visually detecting LFN sounds, recordings were down-sampled from 96 to $32 \mathrm{kHz}$ before scanning recordings.

We based our identification of bray sounds on dos Santos et al.'s (1995) and Janik's (2000a) description. Brays are distinct vocal units composed of two constituent sound types: a BP and a short down sweep (Janik 2000a), the latter of which is structurally similar to an LFN sound (Simard et al. 2011). We investigated the temporal patterning of BP and LFN sounds to look for evidence of bray production (dos Santos et al. 1995; Janik 2000a). As the exact temporal patterning of components in bray sounds is poorly defined in the literature, we investigated bray production by looking for BP and LFN sounds produced according to two criteria, one stricter than the other: (1) we defined a bray unit as consisting of a BP followed by an LFN sound produced within a time period of $0-0.5$. Such brays could be produced individually or in sequences. (2) We used a more relaxed criteria and looked for BP and LFN sounds alternating within a time frame of $0-2.0 \mathrm{~s}$, whereby either LFN or BP sounds could start the sequence and up to three sounds of the same type could be produced in a row before switching back to the alternative sound type. Therefore, a sequence of LFN-BP-BP-LFN-BP-BP-LFNBP for example, could be included in this definition. We measured intervals from the end of one sound to the start of the next. We assumed that BP sounds and LFN sounds could not overlap in time, with overlapping sounds removed and the inter-sound intervals recalculated.

Whistles are narrow-band tonal signals longer than $0.1 \mathrm{~s}$ in duration (Lilly and Miller 1961; Janik et al. 2013). We included only those where at least part of the fundamental frequency was above $3 \mathrm{kHz}$ (Gridley et al. 2012). This distinguishes whistles from other narrow-band sounds produced by bottlenose dolphins (van der Woude 2009; Simard et al. 2011). Whistles interrupted by very short breaks $(<0.03 \mathrm{~s})$ were considered as continuous, but no attempt was made to identify disconnected multiloops (Esch et al. 2009b; 
Janik et al. 2013) or signature whistles (Caldwell et al. 1990) in the whistle repertoire. Signature whistles in this population are described elsewhere (Kriesell et al. 2014). Geographic variation in whistle parameters was assessed by comparing our mean values for 6 standard whistle parameters with published data from 12 other regions where the mean and standard deviation (SD) of the vocalization parameter were available.

Chirps are poorly described in the literature but described as: "audible sounds that sweep through a wide frequency range in a fraction of a second" (see Griffin 1959, cited in; Caldwell et al. 1990). We defined chirps as short, stereotyped tonal upsweeps following Janik et al. (2013, Figure 3B). To distinguish chirps from whistles, we set the maximum allowable length for chirps as $0.1 \mathrm{~s}$.

Each tonal sound (LFN, whistle, and chirp) identified was visually assessed and graded based on the signal-to-noise ratio (SNR) as follows: (1), signal is faint but visible on the spectrogram, (2), signal is clear and unambiguous, (3), signal is prominent and dominates. High-quality sounds were those assessed as SNR 2 or 3, which had a clear start/end and were not masked by simultaneous sound. The duration, number of harmonics (LFN only) and inflection points i.e. change in slope from positive to negative or vice versa (whistles only) was assessed from visual inspection of the spectrogram in Adobe Audition. Other frequency characteristics including start, end, minimum, maximum and peak frequency were measured in Raven using the selection function.

\section{Results}

Between 2009 and 2012, we made recordings during 59 encounters with bottlenose dolphins in Walvis Bay. In total, $72 \mathrm{~h}$ of acoustic recordings were made over varying behavioural states (resting, travelling, socializing, surface feeding and milling) and group compositions. The best estimates for group sizes during encounters in which recordings were made ranged from 1 to 50 animals $(\bar{x}=11, \pm \mathrm{SD}=9)$ and $32 \%$ of groups encountered contained calves. Our analysis focused on identification and characterization of four sound types (BP, LFN, whistle, chirp), and the combined sound, the bray, which could not be identified with certainty.

Summary statistics for the acoustic parameters of sounds identified are presented in Table 2, including the mean, $\mathrm{SD}$ and coefficient of variation $(\mathrm{CV}=\mathrm{SD} / \bar{x} \times 100)$. Of the 2475 BP sounds identified a quarter were analysed in detail. In some cases, the pulse repetition rate could be measured using the harmonic interval, but the duration could not be measured, for example due to masking at either the start or end of the sound, explaining the different sample sizes for these parameters $(n=598$ durations, $n=604$ pulse repetition rates, $n=565$ BPs where both measurements could be made). The BP sounds ranged from 0.07 to $3.61 \mathrm{~s}$ in duration with most $(90 \%)$ lasting less than $1 \mathrm{~s}$ $(\bar{x}$ duration $=0.52 \mathrm{~s}, \pm \mathrm{SD}=0.47 \mathrm{~s}$, median $=0.38 \mathrm{~s})$ (Figure 3$)$. Mean pulse repetition rate was $507 \mathrm{p} / \mathrm{s}( \pm \mathrm{SD} 193 \mathrm{p} / \mathrm{s})$ and Pearson's correlation indicated a weak positive association between BP sound duration and pulse repetition rate $(r=0.28)$. Compared with the range of pulse repetition rates $(150-1050 \mathrm{p} / \mathrm{s})$, the inter-quartile range was narrow $(160 \mathrm{p} / \mathrm{s})$ with half of the BP sounds produced at rates between 390 and $550 \mathrm{p} / \mathrm{s}$ (Figure 4). However, a notable proportion of BP sounds (11\%) were produced with high pulse repetition rates, ranging between 801 and the maximum rate of $1050 \mathrm{p} / \mathrm{s}$.

In total, 482 LFN sounds were identified with confidence, of which 311 were high enough quality to be analysed (Table 2). A further 126 probable LFN sounds were identified but not included in any formal analysis. We recorded LFN sounds during only 7 encounters (i.e. $12 \%$, or $14 \%$ if probable LFNs are considered) with bottlenose dolphins. 


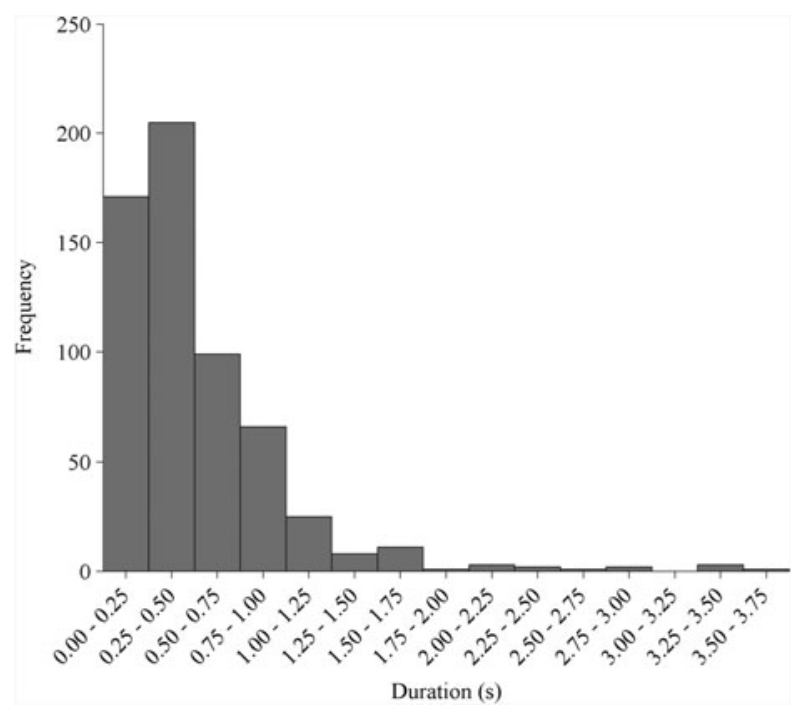

Figure 3. The distribution of sound duration for BP sounds produced by common bottlenose dolphins in Walvis Bay, Namibia. The majority of sounds (90\%) lasted less than $1 \mathrm{~s}$ in duration.

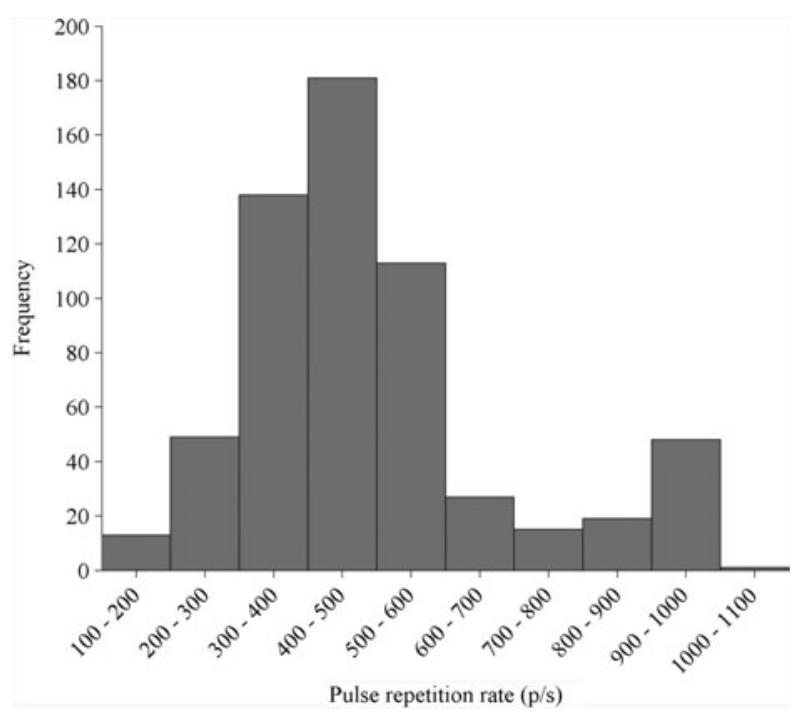

Figure 4. The distribution of pulse repetition rates (p/s) for BP sounds produced by common bottlenose dolphins in Walvis Bay, Namibia.

The LFN sounds analysed were highly stereotyped in nature, characterized by a down swept or constant fundamental frequency and by a waveform with a clear sinusoidal structure (Figure 5). The peak frequency ranged from 0.19 to $0.63 \mathrm{kHz}(\bar{x} 0.35 \mathrm{kHz} \pm \mathrm{SD}$ $0.06 \mathrm{kHz}$ ) and was almost always contained in the fundamental frequency. Compared with whistles and chirps, the frequency range was very narrow $0.43 \mathrm{kHz}( \pm \mathrm{SD} 0.10 \mathrm{kHz})$, with mean minimum and maximum frequencies of $0.16 \mathrm{kHz}( \pm \mathrm{SD} 0.04 \mathrm{kHz})$ and $0.59 \mathrm{kHz}$ $( \pm \mathrm{SD} 0.10 \mathrm{kHz})$ respectively. On average, LFN sounds lasted $0.07 \mathrm{~s}( \pm \mathrm{SD} 0.02 \mathrm{~s})$ in 
Table 2. Acoustic characteristics of sound types produced by bottlenose dolphins in Walvis Bay, Namibia.

\begin{tabular}{|c|c|c|c|c|c|c|c|c|c|c|c|}
\hline $\begin{array}{l}\text { Sound } \\
\text { type }\end{array}$ & Statistics & $\begin{array}{l}\text { Start freq } \\
(\mathrm{kHz})\end{array}$ & $\begin{array}{l}\text { End freq } \\
(\mathrm{kHz})\end{array}$ & $\begin{array}{l}\text { Min freq } \\
(\mathrm{kHz})\end{array}$ & $\begin{array}{l}\text { Max freq } \\
(\mathrm{kHz})\end{array}$ & $\begin{array}{l}\text { Freq range } \\
(\mathrm{kHz})\end{array}$ & $\begin{array}{l}\text { Peak freq } \\
(\mathrm{kHz})\end{array}$ & $\begin{array}{l}\text { Inflection } \\
\text { points }(n)\end{array}$ & Duration (s) & $\begin{array}{l}\text { Number of } \\
\text { harmonics }\end{array}$ & $\begin{array}{l}\text { Pulse rep } \\
\text { rate }(\mathrm{p} / \mathrm{s})\end{array}$ \\
\hline \multirow[t]{4}{*}{ BP } & $n$ & - & - & - & - & - & - & - & 598 & - & 604 \\
\hline & Mean $( \pm \mathrm{SD})$ & - & - & - & - & - & - & - & $0.52(0.47)$ & - & 507 (193) \\
\hline & Range & - & - & - & - & - & - & - & $0.07-3.61$ & - & $150-1050$ \\
\hline & $\mathrm{CV}$ & - & - & - & - & - & - & - & 90 & - & 38 \\
\hline \multirow[t]{4}{*}{ LFN } & $n$ & - & - & 311 & 311 & 311 & 311 & - & 311 & 311 & - \\
\hline & Mean $( \pm$ SD $)$ & - & - & $0.16(0.04)$ & $0.59(0.10)$ & $0.43(0.10)$ & $0.35(0.06)$ & - & $0.07(0.02)$ & 1.03 & - \\
\hline & Range & - & - & $0.03-0.26$ & $0.34-0.96$ & $0.23-0.80$ & $0.19-0.63$ & - & $0.03-0.22$ & $0-7$ & - \\
\hline & $\mathrm{CV}$ & - & - & 0.22 & 0.17 & 0.23 & 0.17 & - & 0.32 & - & - \\
\hline \multirow{4}{*}{ Whistles } & $n$ & 693 & 693 & 693 & 693 & 693 & 693 & 693 & 693 & - & - \\
\hline & Mean $( \pm \mathrm{SD})$ & $8.64(3.56)$ & $7.21(3.10)$ & $5.72(1.99)$ & $12.88(2.87)$ & $7.16(3.24)$ & $8.43(2.42)$ & $1.60(2.12)$ & $1.11(0.65)$ & - & - \\
\hline & Range & $1.76-21.52$ & $1.58-21.09$ & $1.58-16.30$ & $6.05-23.24$ & $0.86-19.59$ & $2.06-18.00$ & $0.00-20$ & $0.10-3.70$ & - & - \\
\hline & $\mathrm{CV}$ & 41 & 43 & 35 & 22 & 45 & 29 & 133 & 58 & - & - \\
\hline \multirow[t]{4}{*}{ Chirps } & $n$ & 12 & 12 & 12 & 12 & 12 & 12 & - & 12 & - & - \\
\hline & Mean $( \pm \mathrm{SD})$ & $8.17(1.42)$ & 12.97 (1.97) & 7.74 (1.33) & 12.97 (1.97) & $5.23(2.63)$ & 9.17 (1.69) & - & $0.06(0.02)$ & - & - \\
\hline & Range & $5.05-10.75$ & $10.52-16.00$ & $5.05-9.42$ & $10.52-16.00$ & $1.72-10.95$ & $6.00-11.81$ & - & $0.04-0.09$ & - & - \\
\hline & $\mathrm{CV}$ & 17 & 15 & 17 & 15 & 50 & 18 & - & 35 & - & - \\
\hline
\end{tabular}



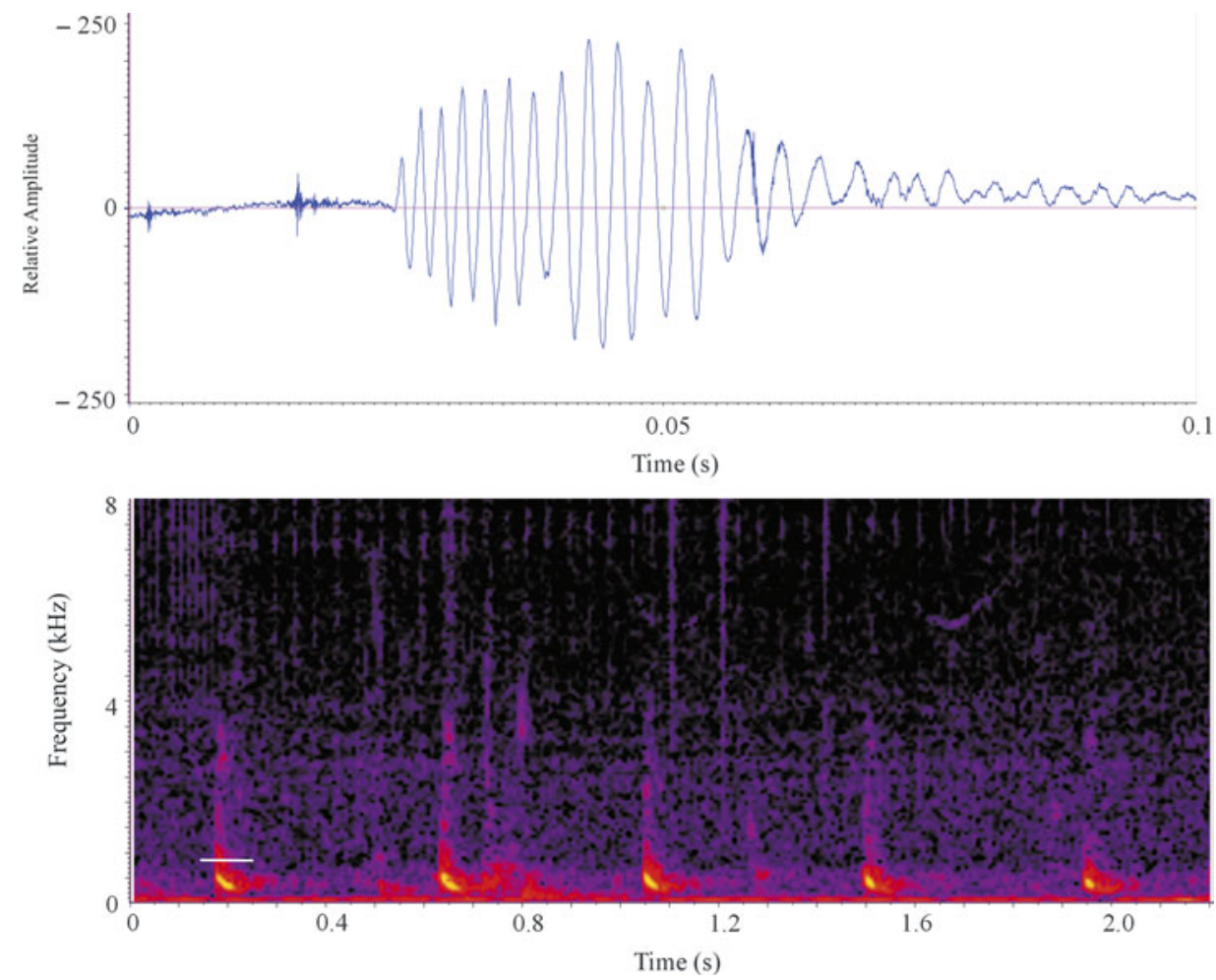

Figure 5. Bottom panel: spectrogram of five LFN sounds produced in a train by common bottlenose dolphins from Walvis Bay, Namibia (spectrogram settings: FFT: 512, Hanning Window, $50 \%$ overlap). Top panel: waveform of the first LFN sound in the spectrogram indicated by the white line, showing the generally sinusoidal structure.

duration. In most cases where it could be assessed ( $81 \%$ of $n=311$ LFNs) they had no or one harmonic (Table 2), although up to seven harmonics above the fundamental frequency were observed. Most LFN sounds were identified in trains and visual inspection of the logsurvivorship plot of inter-LFN intervals (Slater and Lester 1982) under $10 \mathrm{~s}$ demonstrated that a 3-s cut-off was appropriate to separate bouts (Figure 6). Although the behavioural context of LFN sound production was not considered in detail for Walvis Bay, $8 \%$ of LFN sounds occurred during recordings where surface feeding was observed but socializing was not. In all, 33\% were recorded during encounters where animals were observed socializing but not surface feeding, and 59\% were recorded during encounters in which both behavioural states were observed.

Although BP and LFN sounds were often produced in the same recordings, there was little evidence for stereotyped bray vocalizations of alternating BP and LFN sounds as identified in other regions (dos Santos et al. 1995; Janik 2000a). We identified 45 brays following the strict definition of a bray consisting of a BP sound followed by an LFN sound within $0.5 \mathrm{~s}$. Of these, only 15 were observed in series of multiple brays produced in uninterrupted sequences, with the longest sequence consisting of 3 bray units. There were 61 sequences fitting the broader definition of a bray. However, in most cases, the sounds identified within brays lacked the stereotypical characteristics previously described (dos Santos et al. 1995; Janik 2000a). The BP sounds were variable in duration and often the 


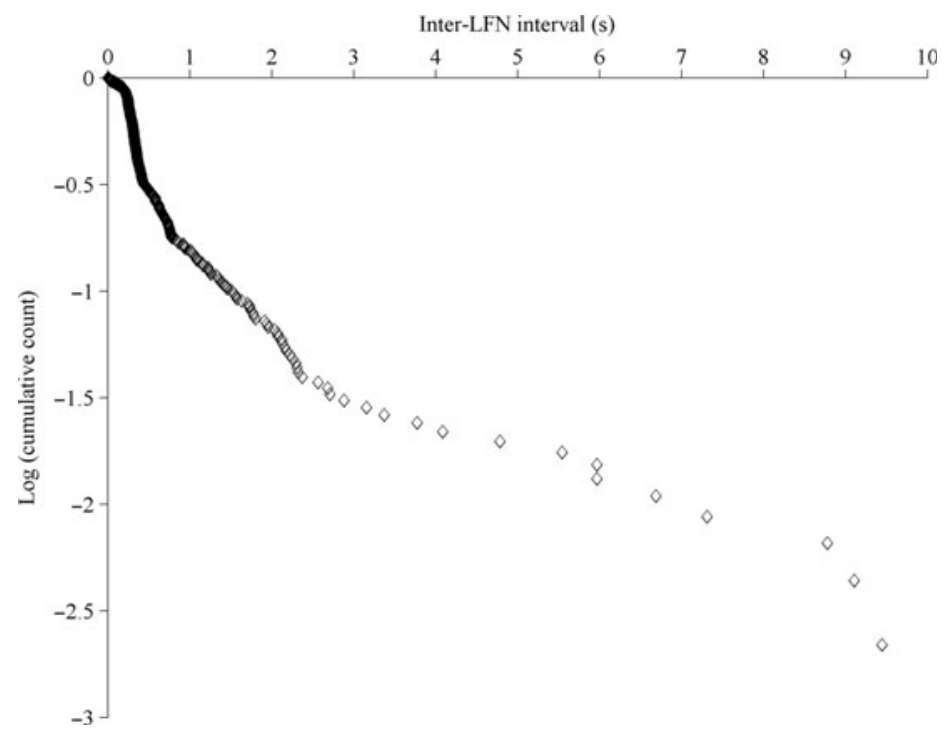

Figure 6. Log survivorship plot of inter-LFN intervals. The change in slope at just under $3 \mathrm{~s}$ demonstrates that most LFNs occurred in trains with short inter-LFN intervals.

amplitude did not match that of the following LFN sound. Also, the time period between the two sound types was usually variable. Consequently, we could not be confident that the two sounds were produced as a unit by the same individual above and beyond what might be expected when several animals are vocalizing at the same time. In summary, the evidence for bray production was weak and could not be confirmed in the Walvis Bay population.

In total, 3027 whistle contours were identified, of which 693 were of a high enough quality to be measured (Table 2). The characteristics of whistles from Walvis Bay bottlenose dolphins fall within the range of those published for other populations of the same species (Figure 7). Whistles ranged from 1.58 to $23.24 \mathrm{kHz}$ in frequency with mean minimum and maximum frequencies of $5.72 \mathrm{kHz}( \pm \mathrm{SD} 1.99)$ and $12.88 \mathrm{kHz}( \pm \mathrm{SD}$ $2.87)$, respectively. Start and end frequencies were broadly similar $(\bar{x} 8.64 \mathrm{kHz} \pm \mathrm{SD}$ 3.56 and $7.21 \mathrm{kHz} \pm$ SD 3.10 for start and end, respectively). Although contour duration was relatively long for Walvis Bay ( $\bar{x} 1.11 \mathrm{~s} \pm \mathrm{SD}$ 0.65) compared with other populations, the number of inflection points was usually low and 74\% of whistles had 0 or 1 inflections. The mean number of inflections ( $\bar{x} 1.60 \pm$ SD 2.12) was offset by a few whistles with many inflection points (maximum 20). Compared with LFN sounds, whistles were highly variable in structure, particularly with regard to the duration, inflection points and frequency range ( $\mathrm{CVs}$ of 45 or more). Whistles were often produced in sequences containing repetitions of the same whistle type, providing strong evidence of signature whistle production (Janik et al. 2013; Kriesell et al. 2014) in the Walvis Bay population.

Chirps were apparently produced infrequently $(n=27)$, identified in only 11 encounters of which 12 chirps were suitable for analysis. These short, stereotyped upswept calls (Figure 8), had a mean minimum frequency of $7.74 \mathrm{kHz}( \pm \mathrm{SD} 1.33 \mathrm{kHz})$ and mean maximum frequency of $12.97 \mathrm{kHz}( \pm \mathrm{SD} 1.97 \mathrm{kHz})$ and were usually produced as single occurrences. A small number of other short $(<0.1 \mathrm{~s})$ tonal calls were also identified $(n=18)$ but did not fit the criteria to be classified as chirps. The frequency modulation 

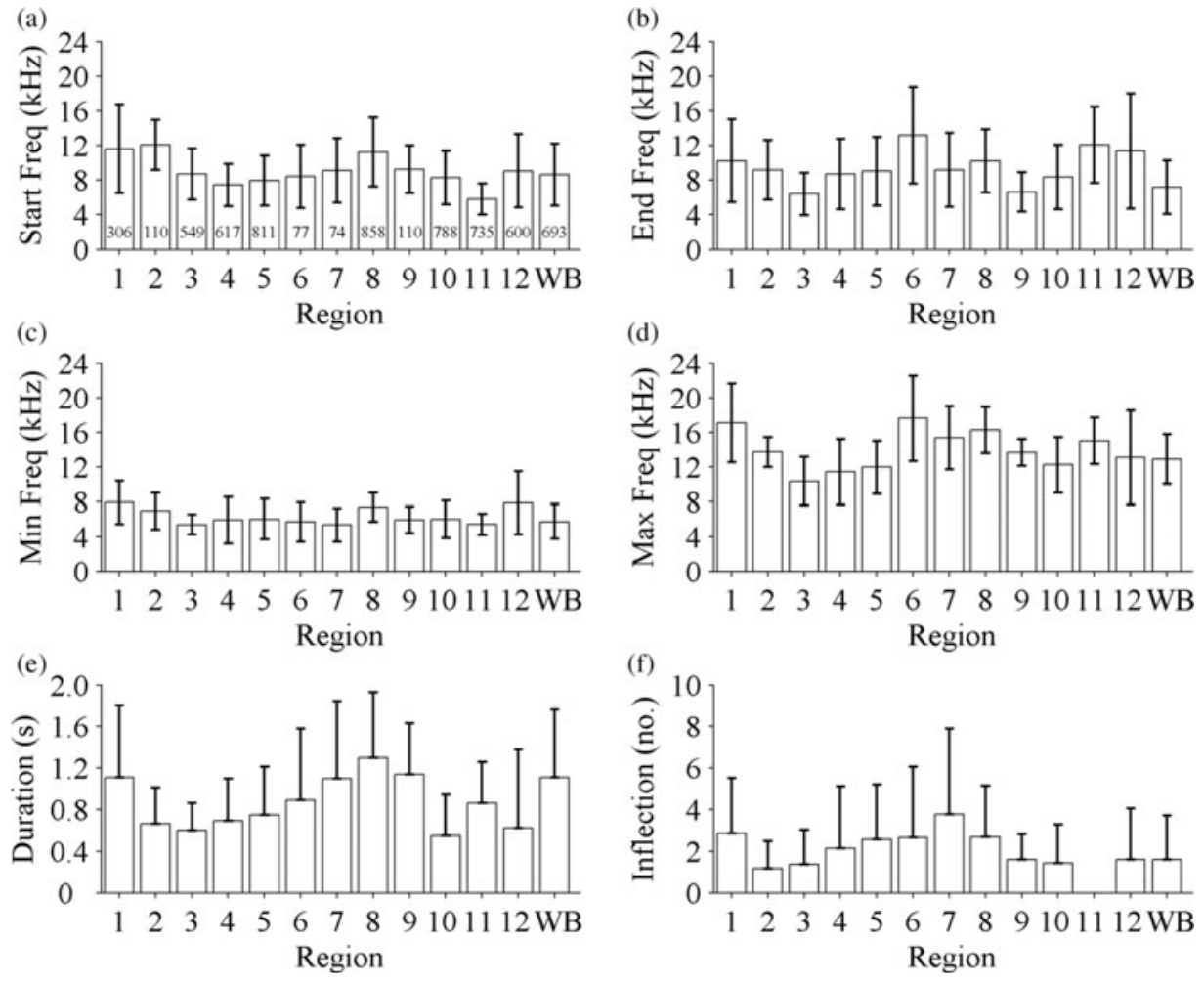

Figure 7. Mean values $( \pm \mathrm{SD})$ for whistle parameters of common bottlenose dolphins from Walvis Bay and 12 other regions. Sample sizes of whistles analysed in each study are displayed within the bars on panel a. Regions are ordered according to where they occur geographically, starting in the North Pacific moving from East to West, ending in Walvis Bay, Namibia. Region codes (and sources) are as follows: (1) North Pacific (Oswald et al. 2007), (2) Gulf of California (Wang et al. 1995b), (3) South Padre Island, Texas (Wang et al. 1995b), (4) Corpus Christi Texas (Wang et al. 1995b), (5) Galveston Texas (Wang et al. 1995b), (6) Gandoca-Manzanillo, Costa Rica (MayCollado and Wartzok 2008), (7) Bocas del Torro, Panamá (May-Collado and Wartzok 2008), (8) Western North Atlantic (Steiner 1981), (9) Golfo de San José, Argentina (Wang et al. 1995b), (10) Patos Lagoon Estuary, South Brazil (Azevedo et al. 2007), (11) Sado Estuary, Portugal (dos Santos et al. 2005), (12) Sardinia, Italy (Díaz López 2011), (WB) Walvis Bay (this study).

pattern of these was down swept, constant or variable in nature or they were closely associated with other whistle contours, suggesting that they were partial whistles (Caldwell et al. 1990). Such contours, however, comprised only a small proportion of the overall sample of tonal sounds produced.

\section{Discussion}

Comprehensively describing a species' repertoire requires considerable sampling over time and behavioural context, and this has rarely been attempted for bottlenose dolphins. Herzing (2000) describes 24 different sound types or combinations that can be produced by dolphins. In comparison, the repertoire of sound types identified in Walvis Bay appears relatively limited and is also considerably smaller than described for common bottlenose dolphins in Fiordland, New Zealand (Boisseau 2005), which have a 12-signal repertoire. 


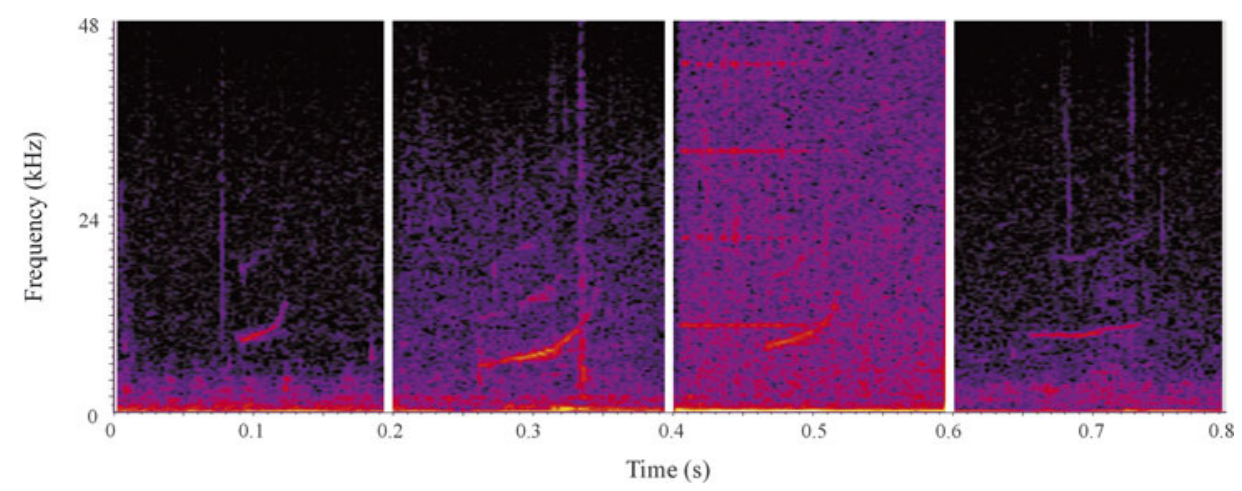

Figure 8. Spectrograms of all chirp sounds analysed from common bottlenose dolphins inhabiting Walvis Bay, Namibia (spectrogram settings: FFT of 512, Hanning window, 50\% overlap).

As bottlenose dolphins exhibit large degrees of behavioural plasticity, both within (Sargeant and Mann 2009) and between (Connor et al. 2000) populations, differences in vocal repertoire likely reflect ecological and cultural variations in sound usage. Methodological differences between researchers may also influence the number of sound types identified, as many studies rely on a largely qualitative analysis of sounds. We kept our groupings very broad, based on clear and consistent physical descriptions. As clear sub-categories could not be identified or linked to surface behaviours further subdivision would have been arbitrary. A more detailed analysis of behavioural context using simultaneous underwater video and acoustic recording equipment (Dudzinski et al. 1995; Herzing 1996) could shed light on the functionality of the sound types described, although the application of this method in Walvis Bay may be hampered by poor underwater visibility. Alternatively, playback experiments provide a powerful tool for investigating functionality of call types in dolphin communication systems (Sayigh et al. 1999; King and Janik 2013).

We distinguished BP sounds from echolocation click trains by their visual characteristics in the spectrogram display (Watkins 1967), a method that is commonly used in studies of BP sounds (Nemiroff and Whitehead 2009; Frankel and Yin 2010; Henderson et al. 2011). Lammers et al. (2003a) suggest a more quantitative definition using a maximum IPI/ICI of $10 \mathrm{~ms}$ to distinguish between BP sounds and echolocation click trains, respectively. Our data demonstrate agreement between the visual inspection and the more quantitative $10 \mathrm{~ms}$ threshold to identify BPs. The majority of BP sounds we identified visually were produced at pulse repetition rates of $300-600 \mathrm{p} / \mathrm{s}$, with only a small proportion $(2.15 \%)$ having pulse repetition rates of $100-200 \mathrm{p} / \mathrm{s}$ and none identified with repetition rates less than $100 \mathrm{p} / \mathrm{s}$ (Figure 4). Given the brief nature of bottlenose dolphin echolocation clicks (equivalent to 0.04-0.07 ms, Au 1993), our pulse repetition rates can be converted into approximate IPIs in ms by dividing 1000 by the repetition rate. In such a way, pulse repetition rates of $100-200 \mathrm{p} / \mathrm{s}$ identified here are equivalent to an approximate IPI/ICI of 5-10 ms. Given that no BP sounds were identified with IPI less than $100 \mathrm{~ms}$, our visual identification from the spectrogram display fitted well with the $10 \mathrm{~ms}$ cut off proposed by Lammers et al. (2003a) and is also in line with analysis of BP sounds conducted by Blomqvist and Amundin (2004).

There are few studies reporting on the characteristics of BP sounds, and their function is likely to vary with species and behavioural context. Their frequent production by bottlenose dolphins seen in this and other studies (Blomqvist and Amundin 2004; Boisseau 
2005) and stereotyped production by species such as the dusky dolphin (Lagenorhynchus obscurus) (Vaughn-Hirshorn et al. 2012) and the northern right whale dolphin (Lissodelphis borealis) (Rankin et al. 2007) provides growing evidence that BP sounds play an important role in intra-specific communication. Communication using BP sounds may be particularly important in species that do not whistle (Dawson 1991) or whistle rarely (Rankin et al. 2007; Vaughn-Hirshorn et al. 2012) and the function of BP sounds in whistling and non-whistling species may therefore differ. For example, in some species, the production of stereotyped BPs may encode individual (Rankin et al. 2007) or group (Ford 1991) identity. We found little evidence of stereotyped BP sounds in our recordings but strong support for signature whistle use in this population (Kriesell et al. 2014). As bottlenose dolphins whistle frequently and use signature whistles to encode identity information (Janik et al. 2006), using BP sounds to communicate identity information may be somewhat redundant in this species.

BP sounds are directional signals (Branstetter et al. 2012) and may be used over short ranges and during interactions in which 'emotively charged' information is shared between conspecifics or perhaps to support visual displays (Lammers et al. 2006). They are commonly associated with social contexts and, in particular, have been linked to aggressive behaviour in captive (Overstrom 1983; Blomqvist and Amundin 2004) and free-ranging (Herzing 2000) bottlenose dolphins. More specifically, Blomqvist and Amundin (2004) often observed short BPs (lasting $<0.5 \mathrm{~s}$ ) during aggressive interactions in captive animals. Short BP sounds were commonly produced by free-ranging bottlenose dolphins in Walvis Bay. The mean duration of BPs identified from this population was $0.52 \mathrm{~s}$ ( \pm SD 0.47), but this arithmetic mean was offset by the few BP sounds of long duration between 1.75 and $3.75 \mathrm{~s}$. In general, the data were skewed towards BP sounds of short duration, with a peak in the distribution at $0.25-0.50 \mathrm{~s}$. The common production of short BP sounds suggests these sound types are important in the repertoire of bottlenose dolphins in Walvis Bay. However, we are yet to establish whether they are associated with heightened emotive or aggressive behaviours or confirm whether they indeed serve a role in intra-specific communication as opposed to echolocation.

A further possible application of BP sounds is in foraging contexts. The low peak frequency of some BPs, which can be outside the frequency range expected for intraspecific communication, and high repetition rate of others, provide evidence that some BP sounds function in prey manipulation. This has been argued for both bottlenose dolphins (Janik 2000a) and killer whales (Simon et al. 2006). We occasionally observed series of BP sounds that were short in duration $(\bar{x}=0.12 \mathrm{~s})$ and had high energy in the low frequency range $(<5 \mathrm{kHz})$, well below the optimum threshold for hearing in bottlenose dolphins (Richardson et al. 1995). However, as we did not have broadband recording equipment, we could not measure the peak frequency of BP sounds across their range, which can often extend into the ultrasonic (Blomqvist and Amundin 2004), and beyond the limits of our recording equipment. We therefore did not attempt to quantify this. As such, the possibility of certain types of BP sounds being involved in feeding interactions remains open and warrants future in depth investigation for the Walvis Bay population.

The LFN sounds we identified were highly stereotyped, low-frequency (peak and fundamental) sounds. In accordance with Simard et al. (2011), we found that LFN sounds were produced infrequently, but when occurring they were usually seen in trains. LFN sounds were produced during 7 encounters or $12 \%$ of encounters with bottlenose dolphins, compared with the $48(81 \%)$ encounters in which whistles were found and $45(76 \%)$ encounters in which BP sounds were identified. Similar proportions have been reported from other sites, for example in the Gulf of Mexico (GOM), LFN sounds were produced 
during $12 \%$ of encounters with dolphins (Simard et al. 2011) and in Scotland whistles were identified from 84\% of encounters (Quick and Janik 2008).

The parameters of LFN sounds have been described from common bottlenose dolphins inhabiting the GOM (GOM: Mississippi Sound [ $n=591]$, Tampa Bay $[n=416]$ and Sarasota Bay [ $n=27]$, Simard et al. 2011) and from Indo-Pacific bottlenose dolphins from Eastern Australia ( $n=200$, Schultz et al. 1995, NB: this population was initially described as T. truncatus but more recently considered T. aduncus; Ansmann et al. 2012). In general, LFN sounds are produced with a similar duration and structure in those populations from which they have been identified. On average, these sounds range in duration from $0.05 \mathrm{~s}$ ( \pm SD $0.04 \mathrm{~s}$, Eastern Australia) to $0.08 \mathrm{~s}$ ( \pm SD $0.04 \mathrm{~s}$, Mississippi Sound), with those recorded from Walvis Bay falling between these limits $(\bar{x}=0.07 \mathrm{~s} \pm$ SD $0.02 \mathrm{~s})$. Like the GOM and Eastern Australia, LFNs sounds from Walvis Bay were simple calls, most having no inflection points and usually descending in frequency over the short duration.

Although the frequency modulation pattern is structurally similar between populations, geographic variation in the frequency content and harmonic structure of LFN sounds is apparent. In the GOM, LFN sounds are produced with many harmonics that occasionally extend into ultrasonic frequencies (Simard et al. 2011). By assessing only LFN sounds with good SNR, we should have detected a complex harmonic structure if it had been present. However, in our study, most LFN sounds we identified had no or just one harmonic. The peak frequency of LFN sounds from Walvis Bay is the lowest for any bottlenose dolphin population so far described, being around three times lower than LFN sounds from Mississippi Sound or Tampa Bay $(\bar{x}=1.06 \mathrm{kHz} \pm \mathrm{SD} 0.58 \mathrm{kHz}$, $\bar{x}=0.93 \mathrm{kHz} \pm \mathrm{SD} 0.42 \mathrm{kHz}$, respectively, Simard et al. 2011). The distribution of energy within the harmonic structure of LFN sounds varies slightly between populations; the peak frequency was almost always contained within the fundamental frequency in Walvis Bay, but was occasionally found in the higher harmonics for the GOM populations (Simard et al. 2011). This may be explained by the heading of the animal relative to the hydrophone, as directional information is encoded in the harmonic structure of some dolphin vocalizations (Lammers and $\mathrm{Au} 2003$ ), or may indicate geographical variation in this property of the sounds. Compared with the GOM, the frequency characteristics of LFN sounds from Eastern Australia Indo-Pacific bottlenose dolphins are more similar to Walvis Bay, with the fundamental frequency ranging from 0.26 to $1.28 \mathrm{kHz}$ and mean minimum and maximum frequencies of $0.56 \mathrm{kHz}( \pm \mathrm{SD} 0.15 \mathrm{kHz})$ and $0.60 \mathrm{kHz}( \pm \mathrm{SD}$ $0.15 \mathrm{kHz}$ ), respectively (Schultz et al. 1995).

Most animals that vocalize produce a repertoire of innate vocalizations, with some species, including bottlenose dolphins, also being capable of vocal production learning (Janik and Slater 1997). In such species, determining whether sounds are innate or learnt can be problematic. Looking for universality of usage in cross-cultural comparisons can provide evidence of innate sound types. For example, the excitement call of Pacific killer whales (Orcinus orca) is used by three different socially and reproductively isolated ecotypes, providing evidence that it may be innately produced (Rehn et al. 2011), which differs from the group-specific discrete pulsed calls that are learnt (Deecke et al. 2000). The conservative form of LFN sounds observed between the three regions (GOM, Namibia and Eastern Australia) and two species of bottlenose dolphin suggests that LFN sounds may also be innate and if so we might expect to find them in more bottlenose dolphin populations. However, the high probability of masking of LFN sounds and inconsistent use of acoustic terminology make it hard to assess universality in LFN production. Standardization of both terminology and methodology would help to clarify the occurrence of LFN sounds in other populations. 
Surface feeding was observed in almost half (47\%) of encounters in which recordings were made, but we found little evidence of bray vocalizations (i.e. alternate BP and LFN sounds produced in rapid succession) in the 72-h data set. It appears that in Walvis Bay, LFN sounds function as distinct units of vocal production, but like Simard et al. (2011) we found that LFN sounds were often produced in series where 'pops' were also heard. Previous studies have found that LFN sounds were associated with socializing activities and heightened emotional contexts such as sexual activity and perhaps aggression (Schultz et al. 1995; Simard et al. 2011). LFN sounds, termed 'grunts', have also been associated with socializing in recordings of S. chinensis (Van Parijs and Corkeron 2001). Although we were limited by observations of surface behaviours only, the available data suggest that LFN sounds and bray sounds serve different functions, with the former principally involved in social interaction and the latter in foraging behaviour and that there is geographic variation in the production of these sound types. Such geographic variation in foraging strategy is common in bottlenose dolphins (Connor et al. 2000). The widespread use of LFN and BP sounds in bottlenose dolphin populations, but the poor evidence for bray production in Walvis Bay, suggests that these sounds are combined together through a process of contextual learning (Janik and Slater 2000). If bray sounds are used to manipulate prey behaviour, populations that feed on salmonids may have learnt to generate these calls to increase foraging success (Janik 2009). This may explain why the bray combined sound is absent in other populations such as Walvis Bay, which exhibit different feeding specializations, feeding mainly on South African mullet (Liza richardsonii) and Silver kob (Argyrosomus inodorus). Future studies should address whether bray vocalizations are only exhibited in populations where salmonids are available prey items.

Soniferous fish produce a range of low-frequency sounds that are superficially similar to the LFN sounds we and others (Schultz et al. 1995; Simard et al. 2011) have ascribed to bottlenose dolphins. Fish calls are generally of low frequency and can be both pulsed and tonal in nature and are often produced in trains (Amorim 2006). The occurrence and sound production characteristics of soniferous fish are poorly described in Namibian waters. As we did not use acoustic localization, we cannot rule out the possibility that some of the LFN sounds we ascribed to dolphins were in fact produced by fish in the environment that the dolphins may, or may not, have been interacting with at the time of recording. However, preliminary analysis of acoustic data collected in 2014 using a static acoustic monitoring device (Loggerhead DSG) deployed in Walvis Bay found a diurnal pattern in biological sounds, which may be attributed to fish, with the majority of sounds recorded during night-time hours. This pattern is commonly observed in other localities (Locascio and Mann 2008). Our recordings with dolphins were made during daylight hours reducing the chance that fish sounds were incidentally included in our analysis. Furthermore, all LFN sounds identified were found in recordings containing all three of the following vocalizations: echolocation clicks, whistles and BP sounds. These sounds were often produced simultaneously with LFN sounds. Any doubtful LFN sounds were assigned a 'probable' status and discounted from analysis. We are therefore confident that the LFN sounds described were generated by bottlenose dolphins.

In line with other studies of bottlenose dolphin communication (Steiner 1981; Wang et al. 1995a,b; Oswald et al. 2003; Morisaka et al. 2005), the duration and number of inflection points of whistles were highly variable (CVs of 58 and 133, respectively, Figure 7). As bottlenose dolphins develop individually distinctive signature whistles in the first year of life (Caldwell and Caldwell 1979; Caldwell et al. 1990), the high variability in these parameters likely reflects differences in the individually distinctive signature 
whistles produced by group members (Kriesell et al. 2014) and may also reflect differences in whistle characteristics due to varying behavioural state (Esch et al. 2009a) or group composition (Caldwell et al. 1990; Janik et al. 2013) during encounters.

Fine-scale geographic variation in some bottlenose dolphin whistle parameters is apparent (Figure 7). Of the six parameters commonly reported, geographic variation in the minimum frequency was the lowest, with less than $3 \mathrm{kHz}$ difference in the mean minimum frequency reported for the 13 populations presented (range $5.34-7.92 \mathrm{kHz}$ ). In contrast, geographic variation in the maximum and end frequency of whistles is greater, ranging between mean population values of $10.33-17.61 \mathrm{kHz}$ and $6.40-13.15 \mathrm{kHz}$, respectively. As minimum frequency appears to be relatively consistent across populations it may be a good parameter for determining species identity through PAM, particularly if the number of potentially whistling species are few, which is the case in Namibia. However, as the whistle parameters of many dolphin species overlap (Oswald et al. 2003; Oswald et al. 2007; Baron et al. 2008), a more robust approach may be whistle classification based on multiple contour features (Gillespie et al. 2013). Future PAM of dolphins in coastal Namibia can use the data collected during this study to train whistle classification systems.

Chirps were more stereotyped than whistles, with a lower CV for most of the frequency parameters measured. In contrast to Janik et al. (2013), chirps were not clearly found in trains. We have little data on the behavioural context of chirp production and with few calls identified it is not clear whether they form a functional sound type differing from whistles. However, in captive contexts, chirps and partial whistles were most often produced when animals were positively reinforced and less often produced when animals were first isolated (Caldwell et al. 1990).

The results of this study demonstrate geographic variation in both the characteristics and sound types used by bottlenose dolphins. Consequently, regionally collected data are necessary to maximize detection probabilities and correct species classification during PAM programmes. The vocal repertoire of the Walvis Bay population is relatively limited, and our data did not support previous observations of bray production in association with feeding behaviour (Janik 2000a) and bray, LFN sounds and chirps were produced too infrequently to be useful indicators of dolphin presence. Future PAM programmes using whistle or echolocation features would be most applicable for this population. These vocalizations were identified in the vast majority of acoustic recordings made and can contain species-specific information (Oswald et al. 2007; Soldevilla et al. 2008; Gillespie et al. 2013). Automated classification using regionally collected data of echolocation clicks or whistles has the greatest chance of providing accurate classification scores, and distinguishing between closely related species or sub-populations of the same species (Soldevilla et al. 2008). Two species of bottlenose dolphin occur in parapatry in southern African waters (T. truncatus and T. aduncus) and both inshore and offshore ecotypes of common bottlenose dolphin are found in Namibian waters (Best 2007). Existing whistle data already show that mean minimum and start frequency values from populations of bottlenose dolphins in Africa (Gridley et al. 2012, this study) may allow for the differentiation of T. aduncus and T. truncatus. However, as the available acoustic data are limited to three populations, more sampling where the two species occur in parapatry is necessary to test this possibility.

The frequency range used by bottlenose dolphins in Walvis Bay overlaps considerably with sources of man-made noise (Richardson et al. 1995), particularly with regard to the tonal sounds described. Consequently, the bottlenose dolphins in Walvis Bay may be susceptible to masking of functionally important sounds from low- and mid-frequency anthropogenic noise sources including that generated from marine tourism (Leeney 2014), 
shipping and coastal construction including the development of a new port in Walvis Bay (Namport 2013). Future management strategies must consider the possible influence of noise pollution on the communication system and long-term fitness of this small coastal population.

\section{Acknowledgements}

This publication is an output from the Namibian Dolphin Project. We are grateful to the interns of Oceans Research for their help collecting these data and particularly X. Indurkhya and N. Tonachella for their enthusiasm. We would like to thank Prof R. Millar and Prof M. Bester for support through the University of Pretoria Mammal Research Institute. Research was conducted with permission from the Namibian Ministry of Fisheries and Marine Resources, and we thank Dr J-P Roux for his support throughout our research activities.

\section{Disclosure statement}

No potential conflict of interest was reported by the authors.

\section{Funding}

TG was funded during the initial stages of this work by NERC PhD studentship, a University of St. Andrews Russell Trust Award and later the University of Pretoria Vice Chancellor's Postdoctoral fellowship. A scholarship from Sapienza University of Rome provided financial support to AN and postdoctoral fellowships from the University of Pretoria and Claude Leon Foundation provided assistance to SE. Equipment and running costs were provided by Idea Wild Fund, Prof V. Janik, and the Nedbank Go Green Fund.

\section{Notes}

1 Email: aur.nast@gmail.com

1 Email: h.kriesell@gmx.de

1 Email: simon.elwen@gmail.com

\section{References}

Altmann J. 1974. Observational study of behaviour: sampling methods. Behaviour 49(3):227-267. Amorim MCP, ed. 2006. Diversity of sound production in fish. Enfield (NH): Science Publishers.

Ansmann IC, Parra GJ, Lanyon JM, Seddon JM. 2012. Fine-scale genetic population structure in a mobile marine mammal: inshore bottlenose dolphins in Moreton Bay, Australia. Mol Ecol 21(18):4472-4485. doi:10.1111/j.1365-294X.2012.05722.x.

Au WWL. 1993. The sonar of dolphins. New York: Springer-Verlag New York, Inc.

Au WWL, Penner RH, Kadane J. 1982. Acoustic behavior of echolocating Atlantic bottlenose dolphins. J Acoust Soc Am 71(5):1269-1275. doi:10.1121/1.387733.

Azevedo AF, Oliveira AM, Dalla Rosa L, Lailson-Brito J. 2007. Characteristics of whistles from resident bottlenose dolphins (Tursiops truncatus) in southern Brazil. J Acoust Soc Am 121(5):2978-2983. doi:10.1121/1.2713726.

Baron SC, Martinez A, Garrison LP, Keith EO. 2008. Differences in acoustic signals from Delphinids in the western North Atlantic and northern Gulf of Mexico. Mar Mamm Sci 24(1):42-56. doi:10.1111/j.1748-7692.2007.00168.x.

Barrett-Lennard LG, Ford JKB, Heise KA. 1996. The mixed blessing of echolocation: differences in sonar use by fish-eating and mammal-eating killer whales. Anim Behav 51(3):553-565. doi:10. 1006/anbe.1996.0059.

Best PB. 2007. Common bottlenose dolphin, Tursiops truncatus. In: Whales and dolphins of the southern African subregion. Cambridge: Cambridge University Press; p. 338.

Blomqvist C, Amundin M. 2004. High-frequency burst-pulse sounds in agnoistic/aggressive interactions in bottlenose dolphins, Tursiops truncatus. In: Thomas J, Moss C, Vater M, editors. Echolocation in bats and dolphins. Chicago (IL): The University of Chicago Press; p. 425-431. 
Blomqvist C, Mello I, Amundin M. 2005. An acoustic play-fight signal in bottlenose dolphins (Tursiops truncatus) in human care. Aquat Mamm 31(2):187-194. doi:10.1578/AM.31.2.2005. 187.

Boisseau O. 2005. Quantifying the acoustic repertoire of a population: the vocalizations of freeranging bottlenose dolphins in Fiordland, New Zealand. J Acoust Soc Am 117(4):2318-2329. doi:10.1121/1.1861692.

Branstetter BK, Moore PW, Finneran JJ, Tormey MN, Aihara H. 2012. Directional properties of bottlenose dolphin (Tursiops truncatus) clicks, burst-pulse, and whistle sounds. J Acoust Soc Am 131(2):1613-1621. doi:10.1121/1.3676694.

Caldwell MC, Caldwell DK. 1979. The whistle of the Atlantic bottlenosed dolphin (Tursiops truncatus) - ontogeny. In: Winn H E, editor. Behaviour of marine animals. New York (NY): Plenum Press; p. 369-401.

Caldwell MC, Caldwell DK, Tyack PL. 1990. Review of the signature-whistle hypothesis for the Atlantic bottlenose dolphin. In: Leatherwood S, Reeves RR, editors. The bottlenose dolphin. San Diego (CA): Academic Press; p. 199-234.

Connor RC, Wells RS, Mann J, Read AJ. 2000. The bottlenose dolphin: social relationships in a fission-fusion society. In: Mann J, Connor RC, Tyack PL, Whitehead H, editors. Cetacean societies. Chicago (IL): The University of Chicago Press; p. 433.

Cook MLH, Sayigh LS, Blum JE, Wells RS. 2004. Signature-whistle production in undisturbed freeranging bottlenose dolphins (Tursiops truncatus). Proc R Soc Lond B Biol Sci 271(1543):1043-1049. doi:10.1098/rspb.2003.2610.

Corkeron PJ, Van Parijs SM. 2001. Vocalizations of eastern Australian Risso's dolphins, Grampus griseus. Can J Zool 79(1):160-164. doi:10.1139/z00-180.

Cornell Bioacoustic Research Program. 2011. Raven Pro: interactive sound analysis siftware (version 1.4). Ithaca (NY): The Cornell Lab of Ornithology. Available from: http://www.birds. cornell.edu/raven

Dawson SM. 1991. Clicks and communication: the behavioural and social contexts of Hector's dolphin vocalizations. Ethology 88(4):265-276. doi:10.1111/j.1439-0310.1991.tb00281.x.

Deecke VB, Ford JKB, Spong P. 2000. Dialect change in resident killer whales: implications for vocal learning and cultural transmission. Anim Behav 60(5):629-638. doi:10.1006/anbe.2000. 1454.

Díaz López B. 2011. Whistle characteristics in free-ranging bottlenose dolphins (Tursiops truncatus) in the Mediterranean Sea: influence of behaviour. Mamm Biol 76:180-189.

dos Santos ME, Ferreira AJ, Harzen S. 1995. Rhythmic sound sequences emitted by aroused bottlenose dolphins in the Sado Estuary, Portugal. In: Kastelein RA, Thomas JA, Nachtigall PE, editors. Sensory systems of aquatic mammals. Woerden: De Spil Publishers; p. 325-334.

dos Santos ME, Louro S, Couchinho M, Brito C. 2005. Whistles of bottlenose dolphins (Tursiops truncatus) in the Sado Estuary, Portugal: characteristics, production rates, and long-term contour stability. Aquat Mamm 31(4):453-462. doi:10.1578/AM.31.4.2005.453.

Dudzinski KM, Clark CW, Würsig B. 1995. A mobile video/acoustic system for simultaneous underwater recording of dolphin interactions. Aquat Mamm 21:187-193.

Elwen SH, Findlay KP, Kiszka J, Weir CR. 2011. Cetacean research in the southern African subregion: a review of previous studies and current knowledge. Afr J Mar Sci 33(3):469-493. doi:10.2989/1814232X.2011.637614.

Esch HC, Sayigh LS, Blum JE, Wells RS. 2009a. Whistles as potential indicators of stress in bottlenose dolphins (Tursiops truncatus). J Mammal 90(3):638-650.

Esch HC, Sayigh LS, Wells RS. 2009b. Quantifying parameters of bottlenose dolphin signature whistles. Mar Mamm Sci 25(4):976-986. doi:10.1111/j.1748-7692.2009.00289.x.

Findlay KP, Best PB, Ross GJB, Cockcroft VG. 1992. The distribution of small odontocete cetaceans off the coasts of South Africa and Namibia. S Afr J Mar Sci 12(1):237-270. doi:10.2989/ 02577619209504706 .

Finneran JJ. 2013. Dolphin "packet" use during long-range echolocation tasks. J Acoust Soc Am 133(3):1796-1810. doi:10.1121/1.4788997.

Ford JKB. 1991. Vocal traditions among resident killer whales (Orcinus orca) in coastal waters of British Columbia. Can J Zool Rev Can Zool 69(6):1454-1483. doi:10.1139/z91-206.

Frankel AS, Yin S. 2010. A description of sounds recorded from melon-headed whales (Peponocephala electra) off Hawai'i. J Acoust Soc Am 127(5):3248-3255. doi:10.1121/1. 3365259. 
Frankel AS, Zeddies D, Simard P, Mann D. 2014. Whistle source levels of free-ranging bottlenose dolphins and Atlantic spotted dolphins in the Gulf of Mexico. J Acoust Soc Am 135(3):1624-1631. doi:10.1121/1.4863304.

Gillespie D, Caillat M, Gordon J, White P. 2013. Automatic detection and classification of odontocete whistles. J Acoust Soc Am 134(3):2427. doi:10.1121/1.4816555.

Gridley T, Berggren P, Cockcroft VG, Janik VM. 2012. Whistle vocalizations of Indo-Pacific bottlenose dolphins (Tursiops aduncus) inhabiting the south-west Indian Ocean. J Acoust Soc Am 132(6):4032-4040. doi:10.1121/1.4763990.

Griffin DR, ed. 1959. Echoes of bats and men. Garden City (NY): Double-Day and Co. (Anchor Books).

Henderson EE, Hildebrand JA, Smith MH. 2011. Classification of behavior using vocalizations of Pacific white-sided dolphins (Lagenorhynchus obliquidens). J Acoust Soc Am 130(1):557-567. doi:10.1121/1.3592213.

Herzing DL. 1996. Vocalizations and associated underwater behavior of free-ranging Atlantic spotted dolphins, Stenella frontalis, and bottlenose dolphins, Tursiops truncatus. Aquat Mamm 22:61-79.

Herzing DL. 2000. Acoustics and social behavior of wild dolphins: implications for a sound society. In: Au WWL, Fay RR, editors. Hearing in whales and dolphins. New York: Springer Handbook of Auditory Research; p. 225-272.

Ivanov MP. 2004. Dolphin's echolocation signals in a complicated acoustic environment. Acoust Phys 50(4):469-479. doi:10.1134/1.1776226.

Janik VM. 2000a. Food-related bray calls in wild bottlenose dolphins (Tursiops truncatus). Proc R Soc Lond B Biol Sci 267(1446):923-927. doi:10.1098/rspb.2000.1091.

Janik VM. 2000b. Whistle matching in wild bottlenose dolphins (Tursiops truncatus). Science 289(5483):1355-1357. doi:10.1126/science.289.5483.1355.

Janik VM. 2009. Acoustic communication in delphinids. Adv Stud Behav 40:123-157.

Janik VM, King SL, Sayigh LS, Wells RS. 2013. Identifying signature whistles from recordings of groups of unrestrained bottlenose dolphins (Tursiops truncatus). Mar Mamm Sci 29(1):109-122. doi:10.1111/j.1748-7692.2011.00549.x.

Janik VM, Sayigh LS, Wells RS. 2006. Signature whistle shape conveys identity information to bottlenose dolphins. Proc Natl Acad Sci USA 103(21):8293-8297. doi:10.1073/pnas. 0509918103.

Janik VM, Slater PJB. 1997. Vocal learning in mammals. Adv Stud Behav 26:59-99.

Janik VM, Slater PJB. 1998. Context-specific use suggests that bottlenose dolphin signature whistles are cohesion calls. Anim Behav 56(4):829-838. doi:10.1006/anbe.1998.0881.

Janik VM, Slater PJB. 2000. The different roles of social learning in vocal communication. Anim Behav 60(1):1-11. doi:10.1006/anbe.2000.1410.

Jones GJ, Sayigh LS. 2002. Geographic variation in rates of vocal production of free-ranging bottlenose dolphins. Mar Mamm Sci 18(2):374-393. doi:10.1111/j.1748-7692.2002.tb01044.x.

Kikusui T, Nakanishi K, Nakagawa R, Nagasawa M, Mogi K, Okanoya K, Brembs B. 2011. Cross fostering experiments suggest that mice songs are innate. PLoS One 6(3). doi:10.1371/journal. pone. 0017721.

King SL, Janik VM. 2013. Bottlenose dolphins can use learned vocal labels to address each other. Proc Natl Acad Sci USA 110(32):13216-13221. doi:10.1073/pnas.1304459110.

Kriesell H, Elwen SH, Nastasi A, Gridley T. 2014. Identification and characteristics of signature whistles in wild bottlenose dolphins (Tursiops truncatus) from Namibia. PLoS One 9:e106317.

Lammers MO, Au WWL. 2003. Directionality in the whistles of Hawaiian spinner dolphins (Stenella longirostris): a signal feature to cue direction of movement? Mar Mamm Sci 19(2):249-264. doi:10.1111/j.1748-7692.2003.tb01107.x.

Lammers MO, Au WWL, Aubauer R, Nachtigall PE. 2003a. A comparative analysis of the pulsed emissions of free-ranging Hawaiian spinner dolphins (Stenella longirostris). In: Thomas JA, Moss CF, Vater M, editors. Echolocation in bats and dolphins. Chicago (IL): The University of Chicago Press; p. 414-419.

Lammers MO, Au WWL, Herzing DL. 2003b. The broadband social acoustic signaling behavior of spinner and spotted dolphins. J Acoust Soc Am 114(3):1629-1639. doi:10.1121/1.1596173.

Lammers MO, Schotten M, Au WWL. 2006. The spatial context of free-ranging Hawaiian spinner dolphins (Stenella longirostris) producing acoustic signals. J Acoust Soc Am 119(2):1244-1250. doi:10.1121/1.2151804. 
Leeney RH. 2014. The marine wildlife-watching tourism industry in Namibia: an overview. J Namibian Sci Soc 62:9-33.

Lilly JC, Miller AM. 1961. Sounds emitted by the bottlenose dolphin: the audible emissions of captive dolphins under water or in air are remarkably complex and varied. Science 133(3465):1689-1693. doi:10.1126/science.133.3465.1689.

Locascio JV, Mann DA. 2008. Diel periodicity of fish sound production in Charlotte Harbor, Florida. Trans Am Fisheries Soc 137(2):606-615. doi:10.1577/T06-069.1.

Long AM, Moore NP, Hayden TJ. 1998. Vocalizations in red deer (Cervus elaphus), sika deer (Cervus nippon), and red x sika hybrids. J Zool Soc Lond 244:123-134.

Lusseau D. 2003. Effects of tour boats on the behavior of bottlenose dolphins: using Markov chains to model anthropogenic impacts. Conserv Biol 17(6):1785-1793. doi:10.1111/j.1523-1739. 2003.00054.x.

Mann J. 1999. Behavioral sampling methods for cetaceans: a review and critique. Mar Mamm Sci 15(1):102-122. doi:10.1111/j.1748-7692.1999.tb00784.x.

May-Collado L, Agnarsson I, Wartzok D. 2007. Phylogenetic review of tonal sound production in whales in relation to sociality. BMC Evol Biol 7(1):136. doi:10.1186/1471-2148-7-136.

May-Collado LJ, Wartzok D. 2008. A comparison of bottlenose dolphin whistles in the Atlantic Ocean: factors promoting whistle variation. J Mammal 89(5):1229-1240. doi:10.1644/07MAMM-A-310.1.

Mitani JC, Hunley KL, Murdoch ME. 1999. Geographic variation in the calls of wild chimpanzees: a reassessment. Am J Primatol 47(2):133-151. doi:10.1002/(SICI)1098-2345(1999)47:2<133: AID-AJP4>3.0.CO;2-I.

Morisaka T, Shinohara M, Nakahara F, Akamatsu T. 2005. Geographic variations in the whistles among three Indo-Pacific bottlenose dolphin Tursiops aduncus populations in Japan. Fisheries Sci 71(3):568-576. doi:10.1111/j.1444-2906.2005.01001.x.

Murray SO, Mercado E, Roitblat HL. 1998. Characterizing the graded structure of false killer whale (Pseudorca crassidens) vocalizations. J Acoust Soc Am 104(3):1679-1688. doi:10.1121/1. 424380.

Namport. 2013. The Walvis Bay SADC Gateway Port Development: Consolidated report on the pre-feasibility studies, May 2013. Ver 1.0. Namibian Ports Authority, Walvis Bay. p. 309.

Nemiroff L, Whitehead H. 2009. Structral characteristics of pulsed calls of long-finned pilot whales Globicephala melas. Bioacoust Int J Anim Sound Recording 19:67-92.

Noad MJ, Cato DH, Bryden MM, Jenner MN, Jenner KCS. 2000. Cultural revolution in whale songs. Nature 408(6812):537. doi:10.1038/35046199.

Nowacek DP. 2005. Acoustic ecology of foraging bottlenose dolphins (Tursiops truncatus), habitatspecific use of three sound types. Mar Mamm Sci 21(4):587-602. doi:10.1111/j.1748-7692. 2005.tb01253.x.

Oswald JN, Barlow J, Norris TF. 2003. Acoustic identification of nine delphinid species in the eastern tropical Pacific Ocean. Mar Mamm Sci 19(1):20-37. doi:10.1111/j.1748-7692.2003. tb01090.x.

Oswald JN, Rankin S, Barlow J, Lammers MO. 2007. A tool for real-time acoustic species identification of delphinid whistles. J Acoust Soc Am 122(1):587-595. doi:10.1121/1.2743157.

Overstrom NA. 1983. Association between burst-pulse sounds and aggressive behavior in captive Atlantic bottlenosed dolphins (Tursiops truncatus). Zoo Biol 2(2):93-103. doi:10.1002/zoo. 1430020203.

Quick NJ, Janik VM. 2008. Whistle rates of wild bottlenose dolphins (Tursiops truncatus): influences of group size and behavior. J Comp Psychol 122(3):305-311. doi:10.1037/07357036.122.3.305.

Quick NJ, Janik VM. 2012. Bottlenose dolphins exchange signature whistles when meeting at sea. Proc R Soc B 279(1738):2539-2545. doi:10.1098/rspb.2011.2537.

Rankin S, Oswald J, Barlow J, Lammers M. 2007. Patterned burst-pulse vocalizations of the northern right whale dolphin, Lissodelphis borealis. J Acoust Soc Am 121(2):1213. doi:10.1121/1. 2404919.

Rehn N, Filatova OA, Durban JD, Foote AD. 2011. Cross-cultural and cross-ecotype production of a killer whale 'excitement' call suggests universality. Naturwissenschaften 98(1):1-6. doi:10. 1007/s00114-010-0732-5.

Rendell LE, Whitehead H. 2003. Vocal clans in sperm whales (Physeter macrocephalus). Proc R Soc Lond B Biol Sci 270(1512):225-231. doi:10.1098/rspb.2002.2239. 
Richardson WJ, Greene Jr, CR, Malme CI, Thomson DH. 1995. Marine mammals and noise. London: Academic Press.

Rossi-Santos MR, Podos J. 2006. Latitudinal variation in whistle structure of the estuarine dolphin Sotalia guianensis. Behaviour 143(3):347-364. doi:10.1163/156853906775897905.

Samarra FIP, Deecke VB, Vinding K, Rasmussen MH, Swift RJ, Miller PJO. 2010. Killer whales (Orcinus orca) produce ultrasonic whistles. J Acoust Soc Am Expr Lett 128:EL205-EL210.

Sargeant BL, Mann J. 2009. Developmental evidence for foraging traditions in wild bottlenose dolphins. Anim Behav 78(3):715-721. doi:10.1016/j.anbehav.2009.05.037.

Sayigh LS, Tyack PL, Wells RS, Solow AR, Scott MD, Irvine AB. 1999. Individual recognition in wild bottlenose dolphins: a field test using playback experiments. Anim Behav 57(1):41-50. doi:10.1006/anbe.1998.0961.

Schultz KW, Cato DH, Corkeron PJ, Bryden MM. 1995. Low frequency narrow-band sounds produced by bottlenose dolphins. Mar Mamm Sci 11(4):503-509. doi:10.1111/j.1748-7692. 1995.tb00673.x.

Schultz KW, Corkeron PJ. 1994. Interspecific differences in whistles produced by inshore dolphins in Moreton Bay, Queensland, Australia. Can J Zool Rev Can Zool 72(6):1061-1068. doi:10. 1139/z94-143.

Simard P, Lace N, Gowans S, Quintana-Rizzo E, Kuczaj, II, SA, Wells RS, Mann DA. 2011. Low frequency narrow-band calls in bottlenose dolphins (Tursiops truncatus): signal properties, function, and conservation implications. J Acoust Soc Am 130(5):3068-3076. doi:10.1121/1. 3641442 .

Simon M, McGregor PK, Ugarte F. 2007. The relationship between the acoustic behaviour and surface activity of killer whales (Orcinus orca) that feed on herring (Clupea harengus). Acta Ethol 10(2):47-53. doi:10.1007/s10211-007-0029-7.

Simon M, Ugarte F, Wahlberg M, Miller LA. 2006. Icelandic killer whales Orcinus orca use a pulsed call suitable for manipulating the schooling behaviour of herring Clupea harengus. Bioacoustics 16(1):57-74. doi:10.1080/09524622.2006.9753564.

Slater PJB, Lester NP. 1982. Minimising errors in splitting behaviour into bouts. Behaviour 79(2):153-161. doi:10.1163/156853982X00229.

Soldevilla MS, Henderson EE, Campbell GS, Wiggins SM, Hildebrand JA, Roch MA. 2008. Classification of Risso's and Pacific white-sided dolphins using spectral properties of echolocation clicks. J Acoust Soc Am 124(1):609-624. doi:10.1121/1.2932059.

Steiner WW. 1981. Species-specific differences in pure tonal whistle vocalizations of five western north Atlantic dolphin species. Behav Ecol Sociobiol 9(4):241-246. doi:10.1007/BF00299878.

van der Woude SE. 2009. Bottlenose dolphins (Tursiops truncatus) moan as low in frequency as baleen whales. J Acoust Soc Am 126(3):1552-1562. doi:10.1121/1.3177272.

Van Parijs SM, Corkeron PJ. 2001. Vocalizations and behaviour of pacific humpback dolphins Sousa chinensis. Ethology 107(8):701-716. doi:10.1046/j.1439-0310.2001.00714.x.

Vaughn-Hirshorn RL, Hodge KB, Würsig B, Sappenfield RH, Lammers MO, Dudzinski KM. 2012. Characterizing dusky dolphin sounds from Argentina and New Zealand. J Acoust Soc Am 132(1):498-506. doi:10.1121/1.4728191.

Wang D, Würsig B, Evans E. 1995a. Comparisons of whistles amoung seven odontocete species. In: Kastelein RA, Thomas JA, editors. Sensory systems of aquatic mammals. Woerden: De Spil Publishers; p. 299-323.

Wang D, Würsig B, Evans WE. 1995b. Whistles of bottlenose dolphins: comparisons among populations. Aquat Mamm 21:65-77.

Watkins WA. 1967. Harmonic interval: fact or artifact in spectral analysis of pulse trains. In: Tavolga WN, editor. Marine bio-acoustics. Oxford: Pergamon Press; p. 15-42. 